This item was submitted to Loughborough's Research Repository by the author.

Items in Figshare are protected by copyright, with all rights reserved, unless otherwise indicated.

\title{
Application of quality function deployment in product design and development: car seat case study
}

PLEASE CITE THE PUBLISHED VERSION

https://doi.org/10.1007/978-981-15-4481-1_9

PUBLISHER

Springer

VERSION

AM (Accepted Manuscript)

PUBLISHER STATEMENT

The final authenticated version is available online at https://doi.org/10.1007/978-981-15-4481-1_9.

LICENCE

CC BY-NC-ND 4.0

\section{REPOSITORY RECORD}

Mat, Shafizal, Mohd Farhe Hussin, Faiz Redza Ramli, Mohd Rizal Alkahari, Mohamad Ridzuan Jamli, Syahibudil Ikhwan Abdul Kudus, and Keith Case. 2020. "Application of Quality Function Deployment in Product Design and Development: Car Seat Case Study”. Loughborough University.

https://hdl.handle.net/2134/14212922.v1. 


\title{
Application of Quality Function Deployment in Product Design and Development: Car Seat Case Study
}

\author{
Shafizal Mat ${ }^{1,2}$, Mohd Farhe Hussin ${ }^{1}$, Faiz Redza Ramli ${ }^{1,2}$, Mohd Rizal Alkahari ${ }^{1,2}$, \\ Mohamad Ridzuan Jamli ${ }^{3}$, Syahibudil Ikhwan Abdul Kudus ${ }^{1,4}$, Keith Case ${ }^{5}$ \\ 1) Fakulti Kejuruteraan Mekanikal, Universiti Teknikal Malaysia Melaka, \\ Hang Tuah Jaya, 76100 Durian Tunggal, Melaka, Malaysia \\ 2) Centre for Advanced Research on Energy, Universiti Teknikal Malaysia Melaka, \\ Hang Tuah Jaya, 76100 Durian Tunggal, Melaka, Malaysia \\ 3) Fakulti Kejuruteraan Pembuatan, Universiti Teknikal Malaysia Melaka, \\ Hang Tuah Jaya, 76100 Durian Tunggal, Melaka, Malaysia \\ 4) Fakulti Teknologi Kejuruteraan Mekanikal \& Pembuatan, Universiti Teknikal Malaysia \\ Melaka, Hang Tuah Jaya, 76100 Durian Tunggal, Melaka, Malaysia \\ 5) School of Mechanical, Electrical and Manufacturing Engineering, Loughborough University, \\ Leicestershire, United Kingdom \\ shafizaleutem.edu.my
}

\begin{abstract}
Quality Function Deployment (QFD) plays a big role in product design and development. It is consisted of several techniques which are very useful and suitable to be applied in whatever field. This project focuses on how the QFD is implemented and applied in designing a car seat. Ergonomics study is important because it helps to analyze the human posture behavior. According to QFD, the process of designing a new product starts from customer's requirement. Then some of concepts are developed as the early picture resulting from the product design specification and customer's requirement. Other techniques were applied such as morphology chart, concept generation and concept screening. These techniques were then lead into concept selection using weighted scoring method. CAD was performed by using SolidWorks CAD software. An ergonomics analysis were also studied to see the final score of the design using RULA analysis. As the result from QFD process, a new ergonomics car seat design is developed.
\end{abstract}

Keywords: Quality Function Deployment, Human Posture, Ergonomics, Rapid Upper Limb Assessment (RULA).

\section{Introduction}

To design a product well, a design teams needs to know what it is they are designing, and what the end-users will expect from it. Quality Function Deployment is a systematic approach to design based on a close awareness of customer desires, coupled with the integration of corporate functional groups. It consists of translating customer desires (for example, the ease of writing for a pen) into design characteristics (pen ink viscosity, pressure on ball-point) for each stage of the product development (Rosenthal, 1992).Ultimately the goal of QFD is to translate often subjective quality criteria into objective ones that can be quantified and measured and which can then be used to design and manufacture the product. It is a complimentary method for determining how and where priorities are to be assigned in product development. Quality Function Deployment was developed by Yoji Akao in Japan in 1966. By 1972 the power of the approach had been well demonstrated at the Mitsubishi Heavy Industries Kobe Shipyard (Sullivan, 1986) and in 1978 the first book on the subject was published in Japanese and then later translated into English in 1994. In Akao's words, QFD "is a method for developing a design quality aimed at satisfying the consumer and then translating the consumer's demand 
into design targets and major quality assurance points to be used throughout the production phase. QFD is a way to assure the design quality while the product is still in the design stage." As a very important side benefit he points out that, when appropriately applied, QFD has demonstrated the reduction of development time by one-half to onethird (Akao, 1990).

The 3 main goals in implementing QFD are:

(i) Prioritize spoken and unspoken customer wants and needs.

(ii) Translate these needs into technical characteristics and specifications.

(iii) Build and deliver a quality product or service by focusing everybody toward customer satisfaction.

QFD uses some principles from Concurrent Engineering in that cross-functional teams are involved in all phases of product development. Each of the four phases in a QFD process uses a matrix to translate customer requirements from initial planning stages through production control. Each phase, or matrix, represents a more specific aspect of the product's requirements. Relationships between elements are evaluated for each phase. Only the most important aspects from each phase are deployed into the next matrix.

Phase 1, Product Planning: Building the House of Quality. Led by the marketing department, Phase 1, or product planning, is also called The House of Quality. Many organizations only get through this phase of a QFD process. Phase 1 documents customer requirements, warranty data, competitive opportunities, product measurements, competing product measures, and the technical ability of the organization to meet each customer requirement. Getting good data from the customer in Phase 1 is critical to the success of the entire QFD process. Phase 2, Product Design. This phase 2 is led by the engineering department. Product design requires creativity and innovative team ideas. Product concepts are created during this phase and part specifications are documented. Parts that are determined to be most important to meeting customer needs are then deployed into process planning, or Phase 3. Phase 3, Process Planning. Process planning comes next and is led by manufacturing engineering. During process planning, manufacturing processes are flowcharted and process parameters (or target values) are documented. Phase 4, Process Control. Finally, in production planning, performance indicators are created to monitor the production process, maintenance schedules, and skills training for operators. Also, in this phase decisions are made as to which process poses the most risk and controls are put in place to prevent failures. The quality assurance department in concert with manufacturing leads Phase 4.

Proper ergonomic design is necessary to prevent repetitive strain injuries, which can develop over time and can lead to long-term disability. Ergonomics (or human factors) is the scientific discipline concerned with the understanding of interactions among humans and other elements of a system, and the profession that applies theory, principles, data and methods to design in order to optimize human well-being and overall system performance. Ergonomics is employed to fulfill the two goals of health and productivity. It is relevant in the design of such things as safe furniture and easy-to-use interfaces to machines. Ergonomics is concerned with the "fit" between people and their technological tools and environments. It takes account of the user's capabilities and limitations in seeking to ensure that tasks, equipment, information and the environment suit each user. To assess the fit between a person and the used technology, ergonomists consider the job (activity) being done and the demands on the user; the equipment used (its size, shape, and how appropriate it is for the task), and the information used (how it is presented, accessed, and changed). Ergonomics draws on many disciplines in its study of humans and their environments including anthropometry, biomechanics, mechanical engineering, industrial engineering, industrial design, kinesiology, physiology and psychology 
In Sabino U., Imaduddin F., Prabowo A. (eds), Proceedings of the 6th International Conference and Exhibition on Sustainable Energy and Advanced Materials, 16-17 October 2019, Surakarta, Indonesia. Published as Lecture Notes in Mechanical Engineering, Springer, Singapore, 81-95, 2020.

\subsection{Ergonomics Car Seat Design}

A car seat is the chair used in automobiles. It is one of the most important components of vehicles and they are place where professional driver spend most of their time. Automotive seat, which are in contact with vehicle occupants, play an important role in improving the comfort and work environment of a driver and passengers. The improvement of automotive seating systems, particularly for the driver, has been the subject of intense interest for many years since a driver feels more fatigue than passengers. The paper describes a large variety of studies and up to date techniques developed for vehicle seats used by different type of transportation system such as trucks, cars, tractors, trains and aircrafts (Fai, T.C, et al., 2007). In designing a comfortable seat, it is important to understand the vibration environment to which individuals are exposed and how well they can tolerate this environment. Moreover, human sensitivity to low-frequency whole-body vibration (WBV) has pointed to ride quality as an important need in seat design (Mayton A.G. et al., 2006).

The standard car seat is designed to support thighs, the buttocks, lower and upper back, and head support. The front driver and passenger seats of most vehicles have three main parts: the seat back (squab), seat base (cushion), and the headrest. These components are usually constructed from foam to provide comfort to the rider. When choosing this product, foam manufacturers must consider the most suitable foam for balancing comfort, support, safety, and recycling properties (ATASED 6). The cushioning agent is especially important when considering that moving cars can transmit vibrations near the human spine's resonant frequency of $3 \mathrm{~Hz}$. The base can usually be moved forward and back on metal railings and may move up and down to adjust to different body types. This movement is accomplished either by manual latches or by electric levers. The standard base span is from the seated rear to just before the knees and the typical squab extends to the shoulders on the average height person. The head support is connected to the top of the squab by two metal circular tube shafts that are permanently attached to the head support and slide into two holes in the squab. The comfort and durability of a car seat depends on the quality and engineering of its four major components: backrest, cushion-spring platform, upholstery, and padding materials. Modern car seats (especially those used in higher-end sedans and SUVs) combine these four elements not only to create attractive silhouettes, but more importantly, to produce ergonomic and safe car seats.

Ergonomic car seats are great for vehicles used for long driving. Some very good car seats are pressurized to conform to the natural shape of every body type so that the passenger's back, neck, and hips are amply supported. When sitting in the car seat your posture is the most important factor when considering your comfort. The positions that drivers assume depend on their anthropometric characteristics, the range and type of adjustments available in the seat package, and each driver's preferred driving position (Ergonomics 1). Common available adjustments deal with concerns such as providing legroom, supplying back support, and giving head support. Available amenities include electric adjustments, choice in fabric covering, and temperature control. Important advancements in this area are of top concern to manufacturers, government officials and of course, consumers. An integral dimension to any seat design is the aspect of safety. As government regulations become more comprehensive, the design of the car seat must deal with more than just seat belts. Positioning of the occupant with respect to the steering wheel must be considered so injury is not caused by the steering wheel or air bag in a collision.

Nowadays, car manufacturers must try predicting car driver size and position to enhance safety in crashes. Occupant protection systems must find information about the driver's chosen seat position and the size of the driver especially if they are exceptionally large or small (Ergonomics 1). Engineers have gone through a series of tests to 
determine whether it is possible to determine driver position to boost safety. This process involves installing sensors in seats, utilizing specific CAE (computer assisted engineering) software for numerical evaluations, and experimental tools for laboratory test rigs and road tests (ATASED 5). Test results proved it possible to determine drivers' head and chest positions relative to potentially injurious elements such as the steering wheel and airbag; it is even possible to determine some physical dimensions of drivers (Pheasant S, 1998). Correct sitting posture at work is essential in helping to avoid neck and back pain. The chair should be comfortable and the controls easy to reach. Adjust the seat and back frequently to suit the task and maintain full back support. The pelvis should be tilted forwards enabling the spine to hold its natural ' $S$ ' shape. The workstation should suit the user with the height and position of the equipment being corrected for their stature. The challenge of designing for the human body is that it comes in so many different sizes and shapes. As a result, a design that may be comfortable for one person can be inappropriate for others. While most people believe it is relaxing, sitting is actually hard on the back because it transfers the full weight of the upper body onto the buttocks and thighs. Sitting, especially for long periods of time, can also cause increased pressure on the intervertebral discs- the springy, shock-absorbing parts of the spine.

The posture of the seated person is dependent on the design of the seat itself, individual sitting habits and the work to be performed. Seated postures are defined as the body position in which the weight of the body is transferred to a supporting area. The biomechanical considerations of seated postures include the spine, arms, and legs. The muscles at the back of the thighs influence the relative position of the spine and pelvis. The location and slope of the work area influence the position of the neck, shoulders, and upper extremities, when an individual is in a seated posture (Harry Saporta, 2000). A comfortable driving posture is essential for ergonomic design for a driver. Driving is different with the seating on the chair. This is because when driver operate the vehicle, whole body are move same the vehicle that move. It can might be risk to the driver get the neck, back and shoulder pain when not adjust the seat properly before drive.

The height and inclination of the seat pan, combined with the position, shape, and inclination of the backrest influences the resulting seated posture. Low back stresses can be reduced with the use of back supports or seat backs. The most important factor in reducing low back stress is the inclination angle of the seat back itself. Leaning the back against an inclined backrest reduces the physical load on the intervertebral discs and the static strain of the back and shoulder muscles. This is due to the loads on the spine being greater when one is seated, as compared to when one is standing. When one is seated, the posterior elements of the spine place a greater load through the intervertebral discs.

The lumbar support should be placed in the lumbar region to achieve a more normal lordotic curvature when in the seated posture. In order to provide as much comfort as possible, the support should be adjustable in both height and size. The seat back width should allow users to be supported without arm interference. The shape should be convex from top to bottom to conform to the normal lordosis, and concave from side to side to conform to human anatomy and support the occupant in the seat. The tilt angle of the backrest should be adjustable. A backrest inclination of about 110 degrees is considered an appropriate posture; however, greater inclination may be desirable by the user. The backrest tilt angle adjustment should be independent so that there is little or no effect on the front seat height or angle. Seats with high backrests are preferred since they provide both lower back and upper back support. To prevent back strain, it is also recommended that seats have lumbar support, because the lumber region is one of the most highly strained parts of the spine when sitting (Harry Saporta, 2000). 
In Sabino U., Imaduddin F., Prabowo A. (eds),

Proceedings of the 6th International Conference and Exhibition on Sustainable Energy and Advanced Materials, 16-17 October 2019, Surakarta, Indonesia. Published as Lecture Notes in Mechanical Engineering, Springer, Singapore, 81-95, 2020.

\section{METHODOLOGY}

\subsection{Conceptual Design}

Conceptual design is the very first phase of a design where drawings are the primary focus, which are comprised of simple plans and sections. These simple drawings should be able to lend themselves easily to more specific sets of plans.

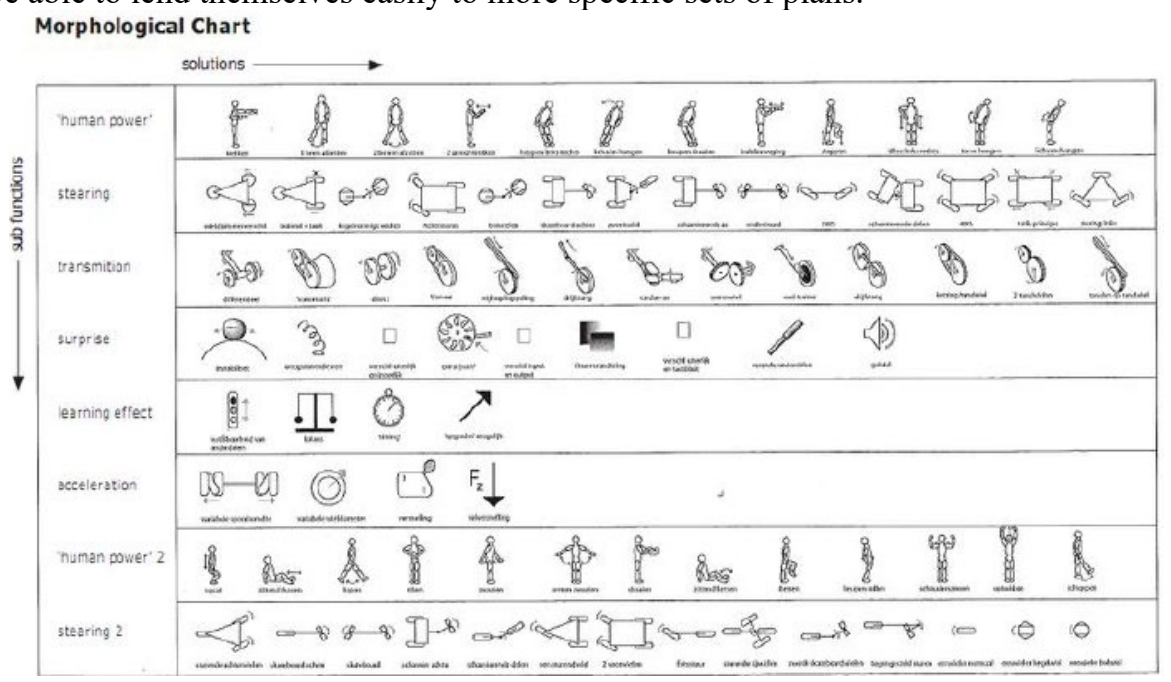

Fig. 1. Example of morphology chart (Roozenburg et al, 1995)

The morphological chart is a method to generate ideas in an analytical and systematic manner (Yusop et al., 2018a). Using the morphological chart, the product's purpose is divided in a set of (sub-) functions. For each of the (sub-) functions ideas are generated and combined into an overall solution. In a morphological chart (Figure 1), possible components are listed based on their functions. Functions are listed in columns, and components are the means that realize the functions are listed in rows. The morphological method thus yields a matrix of functions and components that realize that function. Through careful selection and combination of a set of components, an idea comes about. This idea should be seen as a principle solution: a careful chosen combination of components that together form a conceptual solution (Roozenburg et al, 1995).

The concept screening can be as simple as a checklist of criteria in form of questions that fall into 2 categories: 'must meet' and 'should meet' criteria. Must meet criteria are questions used to determine the viability of the opportunity. These criteria should be structured as closed-ended questions and are designed to provide go/no go decision points. Should meet criteria are often more specific. Pugh's Concept Selection matrix (Pugh method) is a valuable design tool for assessing design trade-off and sparking the creation of useful hybrid concepts. It is best to apply this method after the Voice of the Customer is captured. The Pugh matrix tool is used to facilitate a team-based process for concept generation and selection. A reference concept or base concept is initially selected as the "best current concept". Several other concepts are evaluated according to their strengths and weaknesses against the reference concept. Usually the options are scored relative to the reference concept using a symbolic approach - (one symbol for better than, another for neutral, and another for worse than). Comparison of the scores generated gives insight into the best alternative. The Pugh Method is a disciplined approach that helps create strong alternative concepts from weaker concepts. The advantage of this approach is it is extremely useful because it can help teams arrive at an optimum concept that may actually be a hybrid of the best of all the other concepts. 


\subsection{Product Design Specification}

The product design specification is a listing of the critical parameters, specifications and requirements for the designing product. It is a statement of what the product should be and should do. This is a constantly evolving document. It is subject to change as the project progresses and as more information is learned. Detail is added as the design grows. The product design specification is driven by customer needs and the constraints imposed upon the system. Table 1 shows the product design specification (PDS) of the driver seat. There are nine criteria that take into consideration; performance, environment, maintenance, life in service, size, weight, material, aesthetics and ergonomics respectively. Performance of the seat is the main criteria. It should withstand about 90 $\mathrm{kg}$ of body weight. The seat can be adjusted upward and downward, and forward and backward according to driver's comfortability.

Table 1. Product design specification (PDS) for driver seat

\begin{tabular}{lll}
\hline No & Criteria & Parameter \\
\hline 1 & Performance & $\begin{array}{l}\text { It can support maximum body weight (100kg). It can be } \\
\text { adjustable upward and downward according to lumbar } \\
\text { height and forward and backward according to driver's } \\
\text { comfortability. }\end{array}$ \\
\hline 2 & Environment & $\begin{array}{l}\text { It can withstand hot and cold temperature, vibration and } \\
\text { shock loading of driver. }\end{array}$ \\
\hline 3 & Life in service & It can withstand for $>5$ years. \\
\hline 4 & Maintenance & No need special tools for maintenance and easy cleaning. \\
\hline 5 & Size & It should fit to present car interior. \\
\hline 7 & Meight & $<15$ kg \\
\hline 8 & Aesthetics & Medium density flexible polymer foam. \\
\hline 9 & Ergonomic & $\begin{array}{l}\text { Seat will support body posture. Contour of the seat back } \\
\text { according to driver's lumbar and less sharp edges. }\end{array}$ \\
\hline
\end{tabular}

Second is environment criteria which is the seat withstand hot and cold temperature, vibration and shock loading of driver. Third the seat can withstand about more than 5 years or in other word, it is durable. Fourth, easy cleaning and no need special tools to maintain the seat. This mean the seat is user friendly and burden less. Fifth is about size. Size of the seat should fit to present car interior. This means the seat can be installed in any car. Sixth is weight of the seat. This seat has to be light and easy for installation. Maximum weight of the seat is less or equal to $15 \mathrm{~kg}$. Seventh is about material of the seat and the best material that suit the seat is Medium density flexible polymer foam. Eighth, the seat has to be simple and fulfill customer's need and also sporty look. This parameter explains about aesthetics value. Lastly, according to ergonomics, the seat will support body posture. Contour of the seat back according to driver's lumbar and less sharp edges.

Table 2 shows the additional product design characteristics of car seat. This additional criteria is used as an indicator for development of the seat and to support the previous product design specification. 
In Sabino U., Imaduddin F., Prabowo A. (eds), Proceedings of the 6th International Conference and Exhibition on Sustainable Energy and Advanced Materials, 16-17 October 2019, Surakarta, Indonesia. Published as Lecture Notes in Mechanical Engineering, Springer, Singapore, 81-95, 2020.

Table 2. Additional product design specification (PDS) of car seat

\begin{tabular}{cll}
\hline \multicolumn{1}{c}{ Item } & \multicolumn{1}{c}{ Criteria } & \multicolumn{1}{c}{ Advantage } \\
\hline \multirow{2}{*}{ Usage } & $\begin{array}{l}\text { Easy to use } \\
\text { Easy to operate }\end{array}$ & , Saving time and energy \\
\hline \multirow{2}{*}{ Cheap } & $\begin{array}{l}\text { Low cost production } \\
\text { Use low cost material }\end{array}$ & , Affordable \\
\hline \multirow{2}{*}{ Lifetime } & Can use for a long period of time & , No damaged \\
& & , Saves the cost \\
\hline \multirow{2}{*}{ Quality } & $\begin{array}{l}\text { High quality with low cost material } \\
\text { but durable and high quality. }\end{array}$ & \\
& Consumer meet demand & \\
\hline \multirow{2}{*}{ Market } & Easy to market & , Can be used daily \\
& Faster process & , limited region problem solving \\
\hline
\end{tabular}

\subsection{Concept Development}

As shown in the Figure 2, first concept consist of complex design and shape. Therefore it is also consisted of complex curves section. The backrest is integrated with headrest which means there is restriction for user to adjust the height of the headrest. For advantage of this seat, it gives best support to whole driver's body. The second concept is basically an integrated design. It is look alike as the first concept. It is consisted of complex edges and shape. The headrest and the backrest are fully integrated and it same goes to the first concept. The advantage of this seat is it gives best support for the driver. In addition, this seat is suitable to be used for racing type car. The third concept is not consisted of complex design and shape. In addition there are only minimal curves and edges. The back rest and the headrest is separated which mean the headrest can be adjusted up and down. It gives a good support for driver's body. The fourth concept of seat design also is not consisted of any complex design. It has minimal curves and edges but still give a better support for driver. Other the backrest and headrest are separated. All the curves and edges for the fifth concept are minimal and not too complex. This seat design is one of good design and shape. The backrest and the headrest are separated and this means the headrest can be adjusted up and down according driver's comfort. Other, it gives better support for the driver's body. The sixth concept has very minimal curves and edges but it still gives good support for driver's body. This seat design is one of the designs that consisted of separated backrest and headrest.

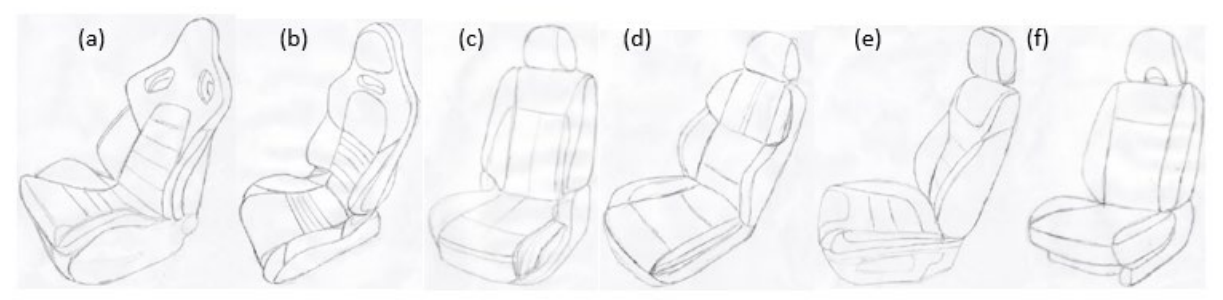

Fig. 2. (a) Concept 1 (b) Concept 2 (c) Concept 3 (d) Concept 4 (e) Concept 5 and (f) Concept 6

Design selection is the process of evaluating concepts with respects to customer needs and other criteria. By comparing the relative strengths and weakness of the concept, and selecting one or more concepts for further investigation, testing and development. The selection of an overall product concept will be focused from the beginning of the development process before selection of the best design is chosen. A design has been developed to find a design requirement by analyzing design sensitivity and by searching for the feasible design region. In addition, the best configuration concept that satisfies the design requirements has been identified using Quality Function Deployment and the Configuration Concept Selection Matrix. This Concept Selection Process can 
contribute to reduce the time and effort during early design stage (Hyeong-Uk Park et al., 2006).

There is having some criteria to make a selection of the product. There are has six step to selection process. The six-steps are:

(i) Prepare the selection matrix based on customer needs.

(ii) Rate the concepts.

(iii) Rank the concepts.

(iv) Combine and improve the concepts.

(v) Select one or more concepts to chosen.

(vi) Reflect on the results and the process.

The selection of the driver seat is related based on the specification that has been state and follow the ergonomics analysis. The selection design of the driver seat must follow the concept screening and concept scoring. The purpose of this stage is to narrow down the number of concepts quickly and to improve the concepts. In order to evaluate concepts effectively, some sort of criteria are needed against which concepts can be evaluated in a semi-quantitative manner. It is important to never compare concepts to one another, but only to the unchanging criteria for evaluation. Comparing one concept to another is a comparison of two variables that is as soon as the concept comparing to changes and the results of the comparison are meaningless.

\subsection{Concept Screening and Scoring}

In Table 3, the selection criteria are listed along of the screening matrix. The matrices focus attention on the customer needs and other decision criteria and on the product concepts for improvement and selection. These criteria are chosen based on customers needs. The selection criteria should be chosen to differentiate among the concepts. After careful consideration, the chosen concept become the benchmark or reference against which all concepts are rated.

Table 3. Concept screening method

\begin{tabular}{|c|c|c|c|c|c|c|c|}
\hline \multirow[b]{3}{*}{ SELECTION CRITERIA } & \multirow{2}{*}{\multicolumn{7}{|c|}{ CONCEPT VARIANTS }} \\
\hline & & & & & & & \\
\hline & 1 & 2 & 3 & 4 & 5 & 6 & REF \\
\hline Ease of handling & - & 0 & + & + & + & + & 0 \\
\hline Ease of use & 0 & 0 & 0 & 0 & + & + & 0 \\
\hline Number readability & 0 & 0 & 0 & + & 0 & 0 & 0 \\
\hline Ergonomics design & + & + & 0 & + & + & 0 & 0 \\
\hline Load handling & + & 0 & 0 & 0 & + & 0 & 0 \\
\hline Manufacturing ease & - & - & + & + & 0 & + & 0 \\
\hline PLUSES & & & & & & & \\
\hline & 2 & 1 & 2 & 4 & 4 & 3 & \\
\hline SAME & 2 & 4 & 4 & 2 & 2 & 3 & \\
\hline MINUS & 2 & 1 & - & - & - & - & \\
\hline NET. & 0 & 0 & 2 & 4 & 4 & 3 & \\
\hline RANK & 4 & 4 & 3 & 1 & 1 & 2 & \\
\hline CONTINUE? & NO & NO & YES & YES & YES & YES & \\
\hline
\end{tabular}

For the score that gathered from the table, the concepts 3, 4, 5 and 6 are selected as a reference concept for the selection design. The concepts follow the customer needs criteria and will be continued for the next process.

Table 4 shows the concept scoring for all car seat design concepts. Concept scoring is used when increased resolution will better differentiate among competing concepts. In this stage, weight the relative importance of the selection criteria and focuses on comparisons with respect the criteria. The concepts scoring are determined by the 
weighted sum of the ratings. The concept which gets the highest score will proceed for the next stage. In this case the fifth concept got the highest score follow by third, sixth, fourth, first and second respectively.

Table 4. Weighted rating method

\begin{tabular}{|c|c|c|c|c|c|c|c|c|c|c|c|c|c|}
\hline & \multicolumn{12}{|c|}{ Concepts } \\
\hline & & \multicolumn{2}{|c|}{1} & \multicolumn{2}{|c|}{2} & \multicolumn{2}{|c|}{3} & \multicolumn{2}{|c|}{4} & \multicolumn{2}{|c|}{5} & \multicolumn{2}{|c|}{6} \\
\hline 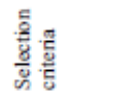 & $\begin{array}{l}\text { 莒 } \\
\frac{0}{0}\end{array}$ & 悹 & 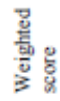 & 䪦 & 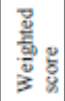 & 竭 & 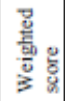 & 此 & 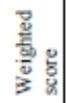 & 耪 & 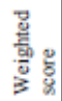 & है & 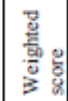 \\
\hline $\begin{array}{l}\text { Ease of } \\
\text { handling }\end{array}$ & $15 \%$ & 2 & 0.3 & 2 & 0.3 & 3 & 0.45 & 3 & 0.45 & 3 & 0.45 & 3 & 0.45 \\
\hline Ease of use & $15 \%$ & 2 & 0.3 & 2 & 0.3 & 4 & 0.6 & 3 & 0.45 & 4 & 0.6 & 3 & 0.45 \\
\hline $\begin{array}{l}\text { Readability of } \\
\text { settings }\end{array}$ & $10 \%$ & 3 & 0.3 & 3 & 0.3 & 3 & 0.3 & 3 & 0.3 & 3 & 0.3 & 4 & 0.4 \\
\hline $\begin{array}{l}\text { Ergonomics } \\
\text { design }\end{array}$ & $25 \%$ & 4 & 0.96 & 3 & 0.75 & 3 & 0.75 & 3 & 0.75 & 4 & 1 & 3 & 0.75 \\
\hline $\begin{array}{l}\text { Ease to } \\
\text { manufacture }\end{array}$ & $20 \%$ & 2 & 0.4 & 2 & 0.4 & 3 & 0.6 & 2 & 0.4 & 3 & 0.6 & 3 & 0.6 \\
\hline \multirow[t]{4}{*}{ Load handling } & $15 \%$ & 2 & 0.3 & 2 & 0.3 & 3 & 0.45 & 4 & 0.6 & 3 & 0.45 & 3 & 0.45 \\
\hline & $\begin{array}{l}\text { Total } \\
\text { score }\end{array}$ & \multicolumn{2}{|c|}{2.56} & \multicolumn{2}{|c|}{2.35} & \multicolumn{2}{|c|}{3.15} & \multicolumn{2}{|c|}{2.95} & \multicolumn{2}{|c|}{3.4} & \multicolumn{2}{|c|}{3.1} \\
\hline & Rank & \multicolumn{2}{|c|}{5} & \multicolumn{2}{|c|}{0} & \multicolumn{2}{|c|}{2} & \multicolumn{2}{|c|}{4} & \multicolumn{2}{|c|}{1} & \multicolumn{2}{|c|}{3} \\
\hline & continue & \multicolumn{2}{|c|}{ No } & \multicolumn{2}{|c|}{ No } & \multicolumn{2}{|c|}{ No } & \multicolumn{2}{|c|}{ No } & \multicolumn{2}{|c|}{ Yes } & \multicolumn{2}{|c|}{ No } \\
\hline
\end{tabular}

Concept 5 is chosen because of firstly this concept meets all the criteria and gained the highest total score after concept scoring and concept screening are performed. By comparing to the others, this concept is the most preferable design because it is the most ergonomically design regarding to all selection criteria in Table 4. Even though there are not too many supports but it can hold and support the whole driver's body. It is also can withstand amount of load. In addition, the backrest and the headrest are separated which mean the headrest can be adjusted according to driver comfortability.

\section{RESULTS AND DISCUSSION}

Figure 3 shows the final seat design. This seat is consisted of four main parts which are seat back, seat base (cushion), side support and headrest. All the drawing processes are performed by using Solid Works CAD software.

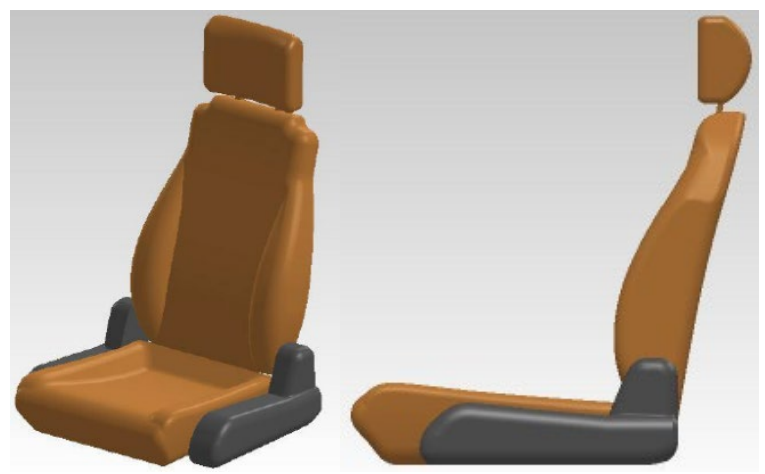

Fig. 3. New seat design

RULA analysis is done to find the ergonomics effect on driver which is given by scale number (Mat, S et al., 2017). The RULA Method was developed and is particularly used to evaluate the risk to workers engaged sedentary tasks such as workers at video terminals or the risk from other tasks in which the operators sits or the risks for workplace in which the worker stands for a large part of the time. The analysis input 
data are body posture (head, trunk, and upper limbs), the force used, and the type of movements or actions performed, repetitively (McAtamney and Corlett, 1993). RULA analysis is used to analyze many facets of manikin posture based on a combination of automatically detected variables and user data (Mat, S et al., 2011). By using data derived from the RULA equations, this analysis:

(i) Considers multiple variables such as object weight, lifting distance, lowering distance, task frequency and action duration.

(ii) Gives you the option of adding task-specific variables such as whether the manikin is externally supported, if the manikin's arms are working across the midline of the body during a task, and whether the manikin's feet are balanced and well supported.

(iii) Creates a Summarized Report of the task.

(iv) Provides a quantified set of results noting whether the task and posture are acceptable, should be investigated further, should be investigated further but changed soon, or should be investigated further but changed immediately.

For this analysis, certain parts of manikin's body will be adjusted according to seat design and not all parts of the body are moved. This is because the body's part that undergo evaluation are back spine, leg, neck and head.

Table 5. RULA analysis score description (McAtamney and Corlett, 1993)

\begin{tabular}{ccl}
\hline Level & Score & \multicolumn{1}{c}{ Description } \\
\hline 1 & 1 or 2 & $\begin{array}{l}\text { Acceptable posture if not } \\
\text { maintained or repeated for } \\
\text { long periods }\end{array}$ \\
\hline 2 & 3 or 4 & $\begin{array}{l}\text { Further investigation } \\
\text { needed and may require } \\
\text { changes }\end{array}$ \\
\hline 3 & 5 or 6 & $\begin{array}{l}\text { Investigation and changes } \\
\text { required soon }\end{array}$ \\
\hline 4 & $>7$ & $\begin{array}{l}\text { Investigation and changes } \\
\text { required immediately }\end{array}$ \\
\hline
\end{tabular}

Table 5 shows the RULA action level and its description. The score is given as number scale from lowest score 1 to the highest score 7 . Each action level has its own descriptions which explain about what are the consequences if the analysis meets the allocated score (Yusop et al., 2018b).

The final score of the final design is 2 as shown in Figure 4. It indicates that posture is acceptable if it is not maintained or repeated for long periods. Regarding to redesigned process, the height of seat back is reduced and the seat back width also is reduced. As the result, the manikin's body is placed perfectly on the seat and the whole body is fully supported. 


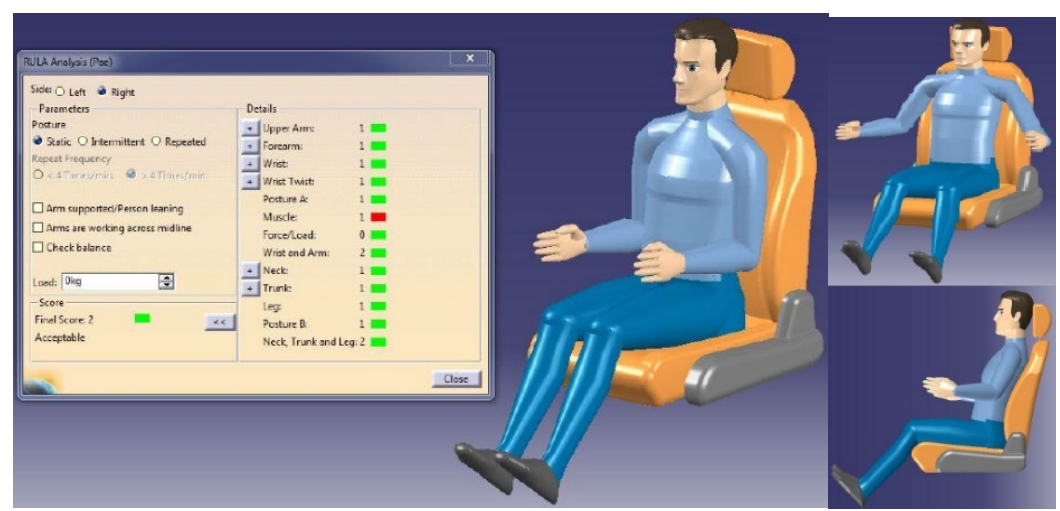

Fig. 4. RULA analysis of final design

Material selection is an important step to determine a comfortable in term of ergonomics. Material selection is a step in the process of designing any physical object. In the context of product design, the main goal of material selection is to minimize cost while meeting product performance goals. Sitting on a hard seat cushion will adversely affect the pelvic bone. For the seat cushion material, elasticity as well as stiffness is required to provide comfort. Also, the material must not be too heavy, with reasonable service life duration and cost. Most importantly, it must provide support for a stable posture. The most optimum material that is identified is medium density flexible polymer foam.

\section{CONCLUSION}

QFD provides a better way of understanding of total design process which starts from customer's requirement until detail design process. All these steps are essential and for example the concept screening. At this stage, concepts that have been generated are filtered to see which the best to be developed is. Other objective that has been achieved is the ergonomics study. Ergonomics study is very important and it has great connection with QFD. This is because, when we develop a product, it has to be analyzed so that it does not harm the users and give benefit to the users. In other words, the product can be used for a long time. One of the analysis that was conducted is rapid upper limb assessment or RULA. This assessment is to analyze the human posture. According to this study, the assessment is about the posture of human sitting. After analysis is done, the seat is optimized and improvised based on the results that are collected.

It is recommended that REBA method could be applied for ergonomics analysis. The REBA Method (Hignett and McAtamney, 2000) was developed to assess the risk of workers in health facilities and other service industries. The analysis input data are the posture of the entire body (head, trunk, upper and lower limbs), the force used, the type or movements or actions performed, repetitively and grasp conditions. A score is assigned to each area or factor examined that increases according to the risk that is inherent in the factor. This is particularly useful during the workplace redesigning phase because it is fairly easy to identify the factors that most contribute to "increasing" the 
risk level. The risk index that is obtained from the REBA analysis indicates the existing risk level and the urgency with which corrective measures should be taken. The scoring evaluation is same as RULA analysis which the higher the score, the greater the risk.

\section{ACKNOWLEDGEMENT}

The authors would like to thank the Centre for Research and Innovation Management (CRIM), Innovation and Sustainability in Machine Technologies Research Group (iSMAT), and Fakulti Kejuruteraan Mekanikal, University Teknikal Malaysia Melaka (UTeM) for registration fees support to participate in ICE-SEAM2019.

\section{REFERENCES}

Akao, Y., Quality Function Deployment: Integrating Customer Requirements into Product Design. Productivity Press, Cambridge, MA (1990).

Fai, T. C., Delbressine, F. and Rauterberg, M. "Vehicle seat design: state of the art and recent development." Proceedings world engineering congress. (2007).

Hignett, S, and McAtamney, L. "Rapid entire body assessment (REBA)." Applied ergonomics 31.2, 201-205, (2000).

Mat, S., Abdullah, M.A., Dullah, A.R., Shamsuddin,. S.A. and Hussin, M.F. Carseat Design using RULA Analysis. Proceeding of Mechanical Engineering Research Day. 130-131, (2017).

Mat, S., Salim, M.A, Wan Mohamad, W.M.F, M. and Yusop, S.M. Design and ergonomics analysis of cutter machine locking device in aerospace industry. Journal of Materials Science and Engineering, 5:145-154 (2011).

Mayton, Alan G., et al. "Laboratory investigation of seat suspension performance during vibration testing." ASME 2006 International Mechanical Engineering Congress and Exposition. American Society of Mechanical Engineers Digital Collection, (2007).

McAtamney, L. and Corlett, E. N. "RULA: a survey method for the investigation of work-related upper limb disorders." Applied ergonomics 24.2, 91-99 (1993).

Park, H. U., Park, M. Y., Lee, S. J., Lee, J. W., \& Byun, Y. H. . "Development of requirement driven design concept selection process in aerospace system." International Conference on Computational Science and Its Applications. Springer, Berlin, Heidelberg, (2006).

Pheasant, S. Bodyspace. Anthropometry, Ergonomics and the Design of Work. (2nd Ed.) London: Taylor \& Francis (1998). 
Roozenburg, N. F. M, and Eekels, J. Product design: fundamentals and methods. Vol. 2. John Wiley \& Sons Inc, (1995).

Rosenthal, S. R. Effective product design and development, how to cut lead time and increase customer satisfaction, Business One Irwin, Homewood, Illinois (1992).

Saporta, H. "Durable ergonomic seating for urban bus operators." Worksite Redesign Program. Oregon OSHA 417 (2000).

Sullivan, L.P., Quality Function Deployment, Quality Progress, pp. 39-50 (1986).

Yusop, M. S. M., Mat, S., Yusuff, M. A., Shamsuddin, S. A., \& Dullah, A. R. Outboard boat engine lifter trolley design in fishing industries. Proceedings of Mechanical Engineering Research Day 2018, 2018, 108-110 (2018).

Yusop, M., Mat, S., Ramli, F. R., Dullah, A. R., \& Khalil, S. N. Design of welding armrest based on ergonomics analysis: Case study at educational institution In Johor Bahru, Malaysia. ARPN Journal of Engineering and Applied Sciences, 13(1), 309-313. (2018). 